\title{
Efficacy comparison of intramedullary nails, locking plates and conservative treatment for displaced proximal humeral fractures in the elderly
}

This article was published in the following Dove Press journal:

Clinical Interventions in Aging

\author{
Wei Ge* \\ Qi Sun* \\ Gen Li \\ Guanghua Lu \\ Ming Cai \\ ShaoHua Li \\ Department of Orthopedics, \\ Shanghai Tenth People's Hospital, \\ Tongji University School of Medicine, \\ Shanghai, People's Republic of China \\ *These authors contributed equally \\ to this work
}

Correspondence: Ming Cai; Shaohua Li Department of Orthopedics, Shanghai Tenth People's Hospital, Tongji University School of Medicine, Shanghai 200072, People's Republic of China

Tel +86 I88 017903 I2;

$+8618930513779$

Fax +86 21 66307580

Email cmdoctor@tongji.edu.cn;

1610710@tongji.edu.cn
Purpose: The incidence of proximal humeral fractures is high in the elderly, and the superior management of these fractures remains a controversy. The study aims to compare clinical outcomes of intramedullary nails, locking plates and conservative treatment for the management of displaced proximal humeral fractures in the elderly.

Patients and methods: In this prospective study, a total of 198 patients with 2- or 3-part proximal humeral fractures who received fixation of locking plates or intramedullary nails or conservative treatment were included. The primary outcome was the 24-month ConstantMurley score. The secondary outcomes included the American Shoulder and Elbow Surgeons (ASES) scores, the visual analog scale (VAS) pain scores, shoulder range of motion and complication rate.

Results: There were no statistically significant differences in the Constant-Murley scores and ASES scores among the plate group, the nail group and the conservative group for 2-part fractures. For 3-part fractures, Constant-Murley scores and ASES scores were lower in the conservative group compared with those in the plate group and the nail group. Besides, the conservative group showed a significantly lower external rotation during follow-ups. The complication rate was comparable among the plate group, the nail group and the conservative group for both 2-part and 3-part fractures.

Conclusion: Similar satisfactory functional outcomes can be achieved with the locking plates, intramedullary nails or conservative treatment for 2-part proximal humeral fractures in the elderly. The advantages in functional outcomes favor locking plates and intramedullary nails in the management of 3-part proximal humeral fractures.

Keywords: proximal humeral fractures, intramedullary nails, locking plates, conservative treatment, the elderly

\section{Introduction}

Proximal humeral fractures are the second most common fracture of upper extremity among older adults and account for $5 \%$ of all adult fractures. ${ }^{1}$ The incidence of proximal humeral fractures is high in elderly people with longer life expectancy. ${ }^{2}$ Non-displaced and minimally displaced fractures, as the majority of proximal humeral fractures, can be managed conservatively to achieve satisfactory shoulder function. ${ }^{3}$ However, for displaced proximal humeral fractures in the elderly, there are various options including surgical and conservative treatments for the management of these fractures.

An open reduction and internal fixation is currently the most common treatment for the majority of displaced proximal humeral fractures. Locking plates and intramedullary nails are commonly used for stable fixation of proximal humeral fractures. ${ }^{4,5}$ 
Good results with locking plates have been reported for displaced proximal humeral fractures, but they are associated with a high rate of complications. ${ }^{6-8}$ Hence, intramedullary nails have become an attractive alternative treatment due to their superior biomechanical advantages including significant stiffness and higher load to failure. ${ }^{9,10}$ However, intramedullary nails do not contribute to satisfactory fracture reduction and the damage to rotator cuff may compromise the shoulder function. ${ }^{11,12}$ Conservative treatment is also an alternative for proximal humeral fractures in the elderly. Although conservative treatment does not achieve stable fracture fixation, better radiographic outcomes and early mobilization, it is reported to lead to a satisfactory shoulder function and lower complication rate. ${ }^{13,14}$

The superior management of displaced proximal humeral fractures in the elderly still remains a controversy. In several previous studies, proximal humeral fractures were treated with intramedullary nails, locking plates or conservative treatment, but various clinical outcomes and complications were reported. ${ }^{12,15,16}$ No consistent conclusion was obtained for the management of proximal humeral fractures. There was only one retrospective study comparing the functional results of locking plates, intramedullary nails and conservative treatment for displaced proximal humeral fractures, but the sample size was not large enough. ${ }^{16}$ Therefore, a high-level evidence trial is needed to explore whether there is a superior treatment option among locking plates, intramedullary nails and conservative treatment for the management of displaced proximal humeral fractures in the elderly. We conducted a prospective study to compare clinical outcomes of locking plates, intramedullary nails and conservative treatment for displaced proximal humeral fractures in the elderly.

\section{Patients and methods}

A total of 198 patients with displaced proximal humeral fractures from February 2010 to December 2014 were recruited in the study. They were scheduled to fixation of locking plates or intramedullary nails or conservative treatment. The inclusion criteria included 2-part proximal humeral fractures or 3-part proximal humeral fractures (as classified with the Neer system) and patients aged $>60$ years. The exclusion criteria were as follows: multiple fractures of ipsilateral upper extremity, open fractures, pathological fractures, concomitant plexus or nerve injuries, and severe mental illness, accompanied by systemic diseases affecting fracture healing. The patients were divided into the plate group (locking plates) or the nail group (intramedullary nails) at discretion of the treating physician and finally of the patient (Figure 1). The patients who declined surgical treatment and only agreed to receive conservative treatment constituted the conservative group. Radiographs including an anteroposterior view of the shoulder, a lateral view of the scapula and a Velpeau axillary view were obtained to confirm the type of fracture. This prospective study was approved by the Committee of Medical Ethics and the institutional review boards of Shanghai Tenth People's Hospital. Written informed consents were obtained from all the patients prior to participation. The study was carried out according to the standards of the Declaration of Helsinki.

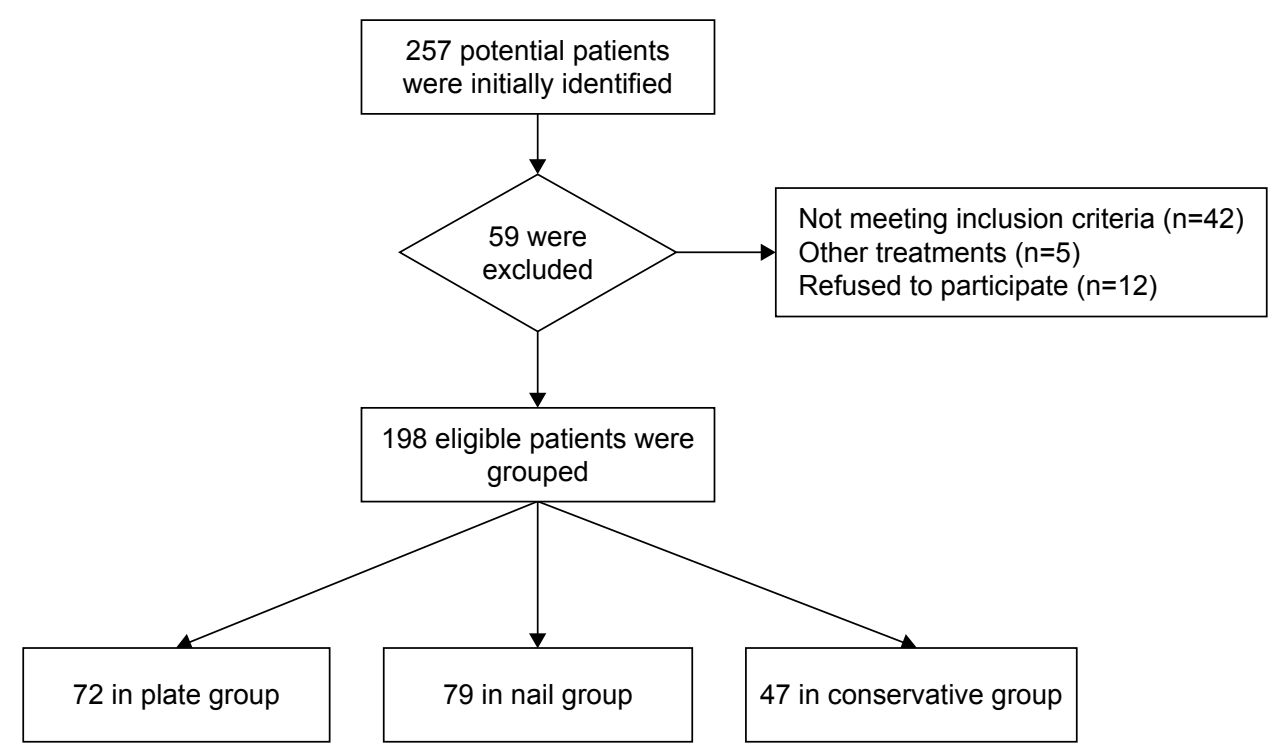

Figure I Flow chart of included patients in the study. 


\section{Intervention and procedures}

All surgeries were performed with patients in beach chair position under general anesthesia.

\section{Plate group}

A deltopectoral approach was used to expose fracture site in the plate group. During further dissection of soft tissue, attention was paid on minimizing the damage to soft tissue and blood supply for fragments. Both direct and indirect reductions were performed to reconstruct anatomy of proximal humerus with the assistance of $\mathrm{C}$ arm fluoroscopy machine. Then, locking plates were positioned lateral to the bicipital groove and $1 \mathrm{~cm}$ inferior to upper humeral greater tuberosity laterally and posteriorly to rehabilitate proximal humerus. Next, a bicortical screw was secured to humeral shaft to fix the plate, and the plate position was checked using a $\mathrm{C}$ arm fluoroscopy machine. A minimum of 5 locking screws were inserted proximally after confirming excellent reduction and plate position, after that more distal locking screws were inserted. Finally, nonabsorbable sutures were used to fix the rotator cuff through the proximal plate holes, and wound was closed carefully.

\section{Nail group}

A deltoid-splitting approach and a rotator cuff incision were performed after closed reduction of the proximal humeral fracture. Then, the entry point was identified after temporary fixation of fracture fragments with Kirschner wires, which was $1 \mathrm{~cm}$ medial to the greater tuberosity. Then, the humeral canal was reamed after introduction of guidewire through entry point. The intramedullary nail connecting with the targeting device was inserted into medullary cavity along with guidewire until the nail reaches below the cartilage. Then, 3 proximal locking screws and 2 distal locking screws were inserted with drill sleeves and targeting sleeves, respectively. Finally, the rotator cuff was sutured with non-absorbable sutures carefully, and wound was closed carefully.

\section{Postoperative rehabilitation regime}

Postoperative rehabilitation regime was same for the plate group and the nail group. A sling bandage was used to stabilize the affected extremity against the chest for 4 weeks. Passive exercises were started on the first postoperative day, while active assistant and active exercises were started 6 weeks postoperatively. Active resisted exercises were started 3 months postoperatively.

\section{Conservative group}

A closed reduction was performed if the displacement of fracture fragment was $>50 \%$ of the diaphyseal diameter, and an X-ray was performed for reduction confirmation. Patients who received conservative treatment were immobilized in a sling bandage stabilizing the arm against the chest for 4 weeks. Passive range of motion exercises were started after 2 weeks, which was supervised by a physical therapist at the first time. The other rehabilitation regime in the conservative group was identical to postoperative rehabilitation regime for the surgical groups.

\section{Follow-up}

Patients were followed up at 2 weeks, 1, 3, 6, 12 and 24 months. A physical examination was done at 6,12 and 24 months postoperatively. The shoulder range of motion was measured using a standard goniometer. The primary outcome was a Constant-Murley score assessed at 24-month follow-up in the study. The American Shoulder and Elbow Surgeons (ASES) scores and a $10 \mathrm{~cm}$ visual analog scale (VAS) score for pain were recorded for further evaluation.

Proximal humeral radiographs were obtained immediately after surgery and at 1, 3, 6, 12 and 24 months. The radiographs were evaluated for bone union, the presence of complication and neck-shaft angle. The bone union was defined as the presence of bridging callus at the fracture site. The complications during the whole follow-up period were recorded, which included osteonecrosis, malunion or nonunion of fracture, penetration of screws and loss of reduction.

\section{Statistical analysis}

Statistical analysis was performed using the SPSS statistical version 19.0 in this study. Continuous variables and categorical variables were summarized as mean \pm standard deviation and absolute number (percentages), respectively. Chi-square test was applied for categorical variables, and Student's $t$-test was applied for normally distributed continuous variable. Mann-Whitney $U$ test was adopted for normally distributed continuous variable. $P<0.05$ was considered as significant difference.

\section{Results}

A total of 184 patients $(92.9 \%)$ completed a minimum of 24 months of follow-up. There were 1, 5 and 3 patients lost to follow-up, and 2, 2 and 1 case of death in the plate group, the nail group and the conservative group, respectively. The demographic characteristics were comparable among each group, and they did not differ in the age, fracture type and medial cortical comminution (Table 1). Ninety-seven patients were with 2-part fractures (38 in the plate group, 36 in the nail 
Table I Demographic characteristics

\begin{tabular}{|c|c|c|c|c|}
\hline Characteristics & $\begin{array}{l}\text { Plate } \\
\text { group } \\
(\mathrm{N}=69)\end{array}$ & $\begin{array}{l}\text { Nail group } \\
(\mathrm{N}=72)\end{array}$ & $\begin{array}{l}\text { Conservative } \\
\text { group }(\mathrm{N}=43)\end{array}$ & P-value \\
\hline Sex, n (\%) & & & & 0.294 \\
\hline Male & $24(35)$ & $22(3 I)$ & $9(2 I)$ & \\
\hline Female & $45(65)$ & $50(69)$ & $34(79)$ & \\
\hline $\begin{array}{l}\text { Age (years) } \\
\text { mean } \pm \text { SD }\end{array}$ & $75.14 \pm 8.46$ & $76.89 \pm 8.12$ & $74.12 \pm 7.65$ & 0.181 \\
\hline \multicolumn{4}{|c|}{ Neer classification, n (\%) } & 0.828 \\
\hline 2-part & $38(55)$ & $36(50)$ & $23(53)$ & \\
\hline 3-part & $31(45)$ & $36(50)$ & $20(47)$ & \\
\hline $\begin{array}{l}\text { Dominant side } \\
\text { involved }\end{array}$ & $37(54)$ & $34(49)$ & $19(44)$ & 0.583 \\
\hline $\begin{array}{l}\text { Medial cortical } \\
\text { comminution }\end{array}$ & $18(26)$ & $21(29)$ & $10(23)$ & 0.780 \\
\hline $\begin{array}{l}\text { Interval between } \\
\text { surgery and injury } \\
\text { (days), mean } \pm S D\end{array}$ & $9.25 \pm 4.29$ & $9.60 \pm 4.14$ & $8.98 \pm 3.98$ & 0.622 \\
\hline
\end{tabular}

group and 23 in the conservative group) and 87 patients with 3 -part fractures (31 in the plate group, 36 in the nail group and 20 in the conservative group). Medial cortical comminution was found in 18 patients in the plate group, 21 patients in the nail group and 10 patients in the conservative group. No differences were observed in bone union time among the plate group (14.2 \pm 2.8 weeks), the nail group (14.6 \pm 3.2 weeks) and the conservative group $(15.1 \pm 2.9$ weeks $)$.

For 2-part proximal humeral fractures, there were no statistically significant differences in the Constant-Murley scores and the ASES scores among the plate group, the nail group and the conservative group (Table 2). At 6-month follow-up, the conservative group showed a statistically higher VAS score and a statistically lesser forward elevation than the plate group and the nail group. No significant differences were found in forward elevation and VAS scores among the plate group, the nail group and the conservative group at 12-month and 24-month follow-up. External rotation was significantly greater in both the plate group and the nail group than in the conservative group during the whole follow-up period, and no statistical difference was observed between the plate group and the nail group (Figure 2).

For 3-part proximal humeral fractures, significantly greater Constant-Murley scores were found in the plate group and the nail group than in the conservative group, and only the plate group showed statistically higher ASES scores than the conservative group (Table 3). The Constant-Murley scores and the ASES scores were comparable between the plate group and the nail group. At 6-month follow-up, the forward elevation was greater in the plate group and the nail group than the conservative group, and the nail group showed higher VAS scores than the conservative group. The VAS score was obviously lower in the plate group than the conservative group, but it did not reach significance $(P=0.066)$. No statistical difference in forward elevation and VAS score was observed among the 3 groups at 12-month and 24-month follow-ups (Figure 3). A significantly lesser external rotation was found in the conservative group, but no statistical difference was found between the nail group and the plate group.

A total of 38 complications were recorded, 18 (26.1\%) (7 in 2-part fractures and 11 in 3-part fractures) in the plate

Table 2 Clinical outcome of locking plates, intramedullary nails and conservative treatment for 2-part proximal humeral fractures

\begin{tabular}{|c|c|c|c|c|c|c|c|}
\hline & & $\begin{array}{l}\text { Plate group, } \\
\text { mean } \pm \text { SD }\end{array}$ & & $\begin{array}{l}\text { Nail group, } \\
\text { mean } \pm \text { SD }\end{array}$ & & $\begin{array}{l}\text { Conservative treatment, } \\
\text { mean } \pm \text { SD }\end{array}$ & \\
\hline \multirow[t]{3}{*}{ Constant-Murley } & 6 months & $62.19(9.72)$ & & $65.44(10.65)$ & & $63.65(10.05)$ & \\
\hline & 12 months & $73.81(8.82)$ & & $73.56(9.76)$ & & $71.5(7)$ & \\
\hline & 24 months & $82.23(7.96)$ & & $82.03(9.12)$ & & $81.85(6.8 I)$ & \\
\hline \multirow[t]{3}{*}{ ASES score } & 6 months & $64.32(9.78)$ & & $63.94(11.47)$ & & $63.45(9.16)$ & \\
\hline & 12 months & $72.81(7.64)$ & & 72.67 (8.99) & & $71.1(6.7)$ & \\
\hline & 24 months & $80.06(9.03)$ & & $81.53(8.88)$ & & $79.9(6.08)$ & \\
\hline \multirow[t]{3}{*}{ Forward elevation } & 6 months & | $48.84(|| .56)$ & $\Delta$ & 147.78 (I3.39) & * & $140.75(10.42)$ & $\Delta, ※$ \\
\hline & 12 months & $153.45(12.18)$ & & $155.86(13.76)$ & & $152.15(14.45)$ & \\
\hline & 24 months & $164.23(9.12)$ & & I $60.78(I 2.7 I)$ & & I59.7 (10.49) & \\
\hline \multirow[t]{3}{*}{ External rotation } & 6 months & $41.39(6.4)$ & $\Delta$ & $40.11(5.14)$ & & $37.2(6.25)$ & $\Delta$ \\
\hline & 12 months & $44.74(5.64)$ & $\Delta$ & $42.97(6.64)$ & & $40.45(5.13)$ & $\Delta$ \\
\hline & 24 months & $48.32(6.92)$ & $\Delta$ & $45.86(8.52)$ & & $42.65(6.93)$ & $\Delta$ \\
\hline \multirow[t]{3}{*}{ VAS score } & 6 months & $1.89(1.13)$ & $\Delta$ & $1.78(1.4)$ & * & $2.55(1.2)$ & $\Delta, ※$ \\
\hline & 12 months & $\mathrm{I} .45(0.8 \mathrm{I})$ & & $1.42(1.05)$ & & $1.65(0.88)$ & \\
\hline & 24 months & $0.8 \mathrm{I}(0.6)$ & & $0.83(0.66)$ & & $0.95(0.5 \mathrm{I})$ & \\
\hline
\end{tabular}

Note: The symbols $\Delta$ and $※$ indicate significant differences between two values with the same symbol in the same line. Abbreviations: ASES, American Shoulder and Elbow Surgeons; VAS, visual analog scale. 


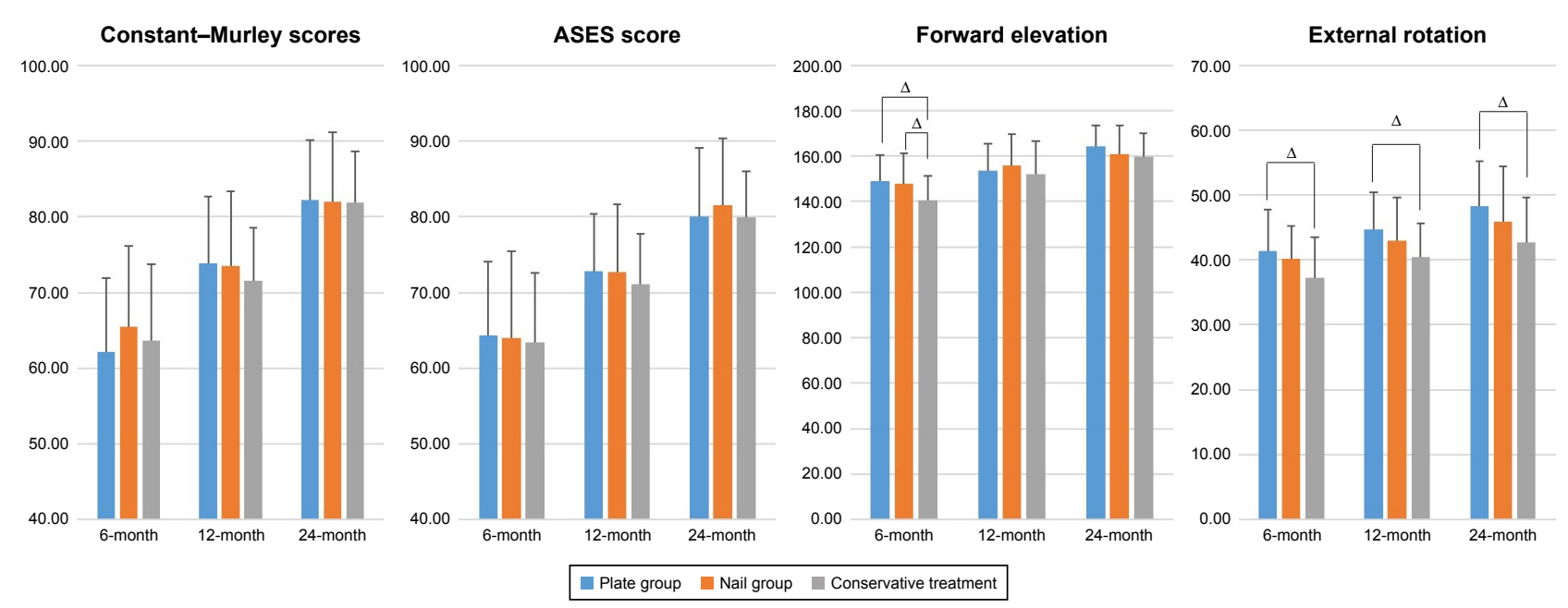

Figure 2 Clinical outcomes of locking plates, intramedullary nails and conservative treatment for 2-part proximal humeral fractures. $\Delta$ indicates significant differences between two values.

Abbreviation: ASES, American Shoulder and Elbow Surgeons.

group, $13(18.1 \%)$ (5 in 2-part fractures and 8 in 3-part fractures) in the nail group and 4 (9.3\%) (1 in 2-part fractures and 3 in 3-part fractures) in the conservative group. No significant difference was found in the total complication rate for 2-part and 3-part proximal humeral fractures among the plate group, the nail group and the conservative group. In the plate group, there were 8 screw penetrations, 3 avascular necrosis, 3 acromion impingement, 2 fracture re-displacement, 1 nonunion and 1 infection. For intramedullary nailing, 6 screw penetrations, 3 rotator cuff injuries, 2 avascular necrosis and 2 fracture displacements were observed. For patients with conservative treatment, there were 2 shoulder stiffness, 1 avascular necrosis and 1 nonunion.

\section{Discussion}

The increasing proportion of elderly people and more active lifestyles increase the incidence of proximal humeral fractures, ${ }^{17}$ and the management of displaced proximal humeral fractures in the elderly remains controversial. We performed a prospective study to evaluate the efficacy of locking plates, intramedullary nails and conservative treatment for the management of displaced proximal humeral fractures in the elderly. We found that locking plates, intramedullary nails and conservative treatment were comparable in recovering shoulder function for 2-part proximal humeral fractures. No significant difference was found in shoulder function scores between the plate group

Table 3 Clinical outcome of locking plates, intramedullary nails and conservative treatment for 3-part proximal humeral fractures

\begin{tabular}{|c|c|c|c|c|c|c|c|}
\hline & & $\begin{array}{l}\text { Plate group, } \\
\text { mean } \pm \text { SD }\end{array}$ & & $\begin{array}{l}\text { Nail group, } \\
\text { mean } \pm \text { SD }\end{array}$ & & $\begin{array}{l}\text { Conservative treatment, } \\
\text { mean } \pm \text { SD }\end{array}$ & \\
\hline \multirow[t]{3}{*}{ Constant-Murley } & 6 months & $62.63(12.16)$ & $\Delta$ & $61.86(10.12)$ & ※ & $55.7(9.74)$ & $\Delta, ※$ \\
\hline & 12 months & 70.24 (9.99) & $\Delta$ & 70.06 (9.62) & $※$ & 64.35 (9.23) & $\Delta, ※$ \\
\hline & 24 months & 79.05 (9.72) & $\Delta$ & 78.81 (8.89) & ※ & 73.17 (8.46) & $\Delta, ※$ \\
\hline \multirow[t]{3}{*}{ ASES score } & 6 months & $61.16(11.58)$ & $\Delta$ & $60.19(10.7)$ & & $55.35(9.21)$ & $\Delta$ \\
\hline & 12 months & 70.25 (8.89) & $\Delta$ & 69.05 (9.68) & & $64.57(9.1)$ & $\Delta$ \\
\hline & 24 months & $78.25(8.74)$ & $\Delta$ & $77.21(10.13)$ & & $72.43(9.7)$ & $\Delta$ \\
\hline \multirow[t]{3}{*}{ Forward elevation } & 6 months & | 42.47 (I4.76) & $\Delta$ & |4|.58 (|2.97) & ※ & I34.74 (I I.66) & $\Delta, ※$ \\
\hline & 12 months & I 48.53 (|4.54) & & I5I.44 (I4.36) & & | 44.74 (I3.78) & \\
\hline & 24 months & I58.I3 (I4.38) & & I 56.44 (I 3.44$)$ & & 151.91 (14.12) & \\
\hline \multirow[t]{3}{*}{ External rotation } & 6 months & $39.29(5.75)$ & $\Delta$ & $37.56(5.47)$ & ※ & $33.26(5.21)$ & $\Delta, ※$ \\
\hline & 12 months & 42.84 (5.69) & $\Delta$ & $40.53(6.3)$ & $※$ & 36.61 (5.53) & $\Delta, ※$ \\
\hline & 24 months & 45.61 (8.17) & $\Delta$ & $43.03(8.12)$ & ※ & $38.48(8.53)$ & $\Delta, ※$ \\
\hline \multirow[t]{3}{*}{ VAS score } & 6 months & $2.37(1.53)$ & & $2.25(1.42)$ & ※ & 3.17 (1.78) & $※$ \\
\hline & 12 months & I.7I (I.04) & & $1.69(1.04)$ & & $2.13(1.1)$ & \\
\hline & 24 months & I.I3 (0.74) & & $\mathrm{I} .03$ (0.69) & & $1.13(0.76)$ & \\
\hline
\end{tabular}

Note: The symbols $\Delta$ and $※$ indicate significant differences between two values with the same symbol in the same line. Abbreviations: ASES, American Shoulder and Elbow Surgeons; VAS, visual analog scale. 

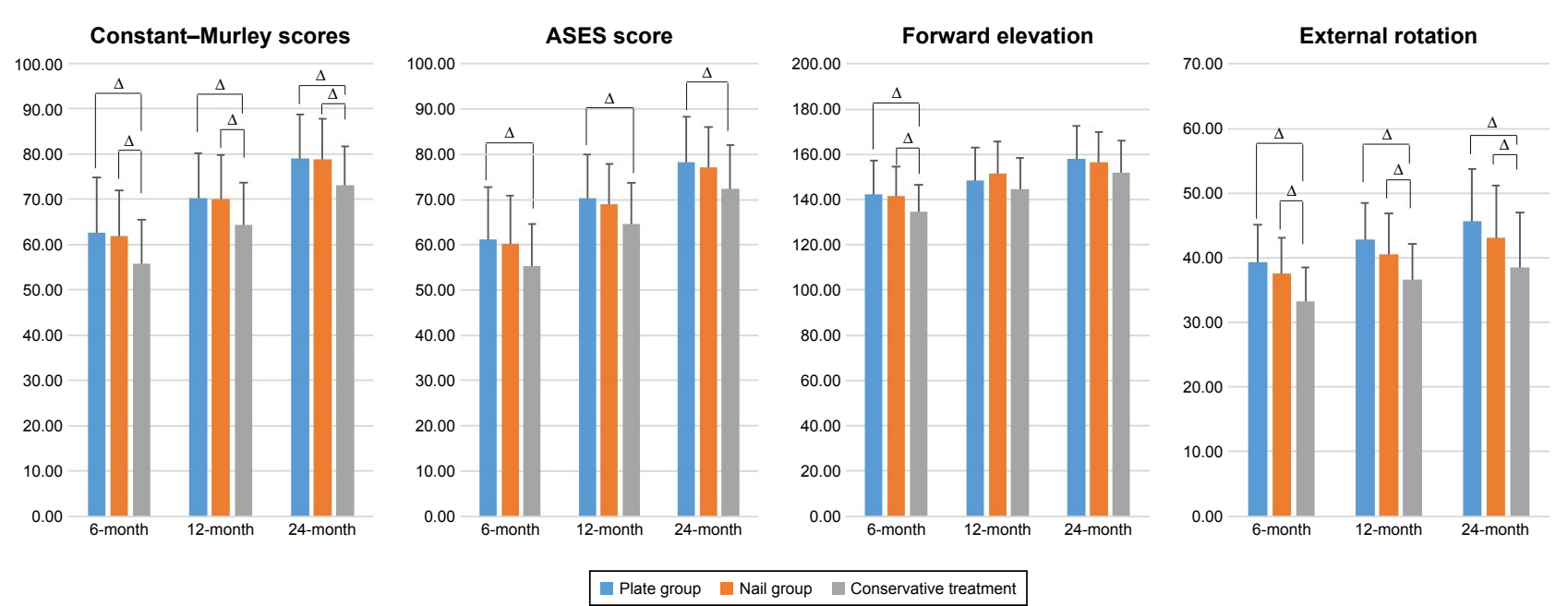

— Plate group nail group $\quad$ Conservative treatment

Figure 3 Clinical outcomes of locking plates, intramedullary nails and conservative treatment for 3-part proximal humeral fractures. $\Delta$ indicates significant differences between two values.

Abbreviation: ASES, American Shoulder and Elbow Surgeons.

and the nail group for 3-part fractures, but they were significantly greater than the conservative group. Both 2-part and 3-part fractures showed a lesser external rotation in the conservative group during the whole follow-up period. There were no statistical differences in forward elevation, VAS score and total complication rate among the 3 groups after final follow-up.

In our study, the plate group and the nail group showed comparable shoulder functional scores for 2-part and 3-part proximal humeral fractures. Several studies demonstrated good clinical outcomes with comparison of intramedullary nails and locking plates in the management of proximal humeral fractures. ${ }^{11,12,15,18-20} \mathrm{Zhu}$ et al ${ }^{12}$ conducted a randomized controlled study to compare functional outcomes between intramedullary nails and locking plates for 2-part proximal humeral fractures and concluded that both implants could achieve satisfactory outcomes in the management of 2-part proximal humeral fractures without statistical difference at the final follow-up. Gracitelli et a ${ }^{15}$ concluded that locking plates and intramedullary nails lead to similar clinical and radiological results in the fixation of 2-part and 3-part proximal humeral fractures. A retrospective study compared 4 common methods in the management of 2-part and 3-4-part proximal humeral fractures and concluded that comparable outcomes were obtained with locking plates and intramedullary nails for 2-part and 3-4-part fractures. ${ }^{16}$ Upon comparing with 2 previous randomized controlled studies, the Constant-Murley scores of our study were similar to those of Gracitelli et al's study, ${ }^{15}$ but inferior to those of Zhu et al's study. ${ }^{12}$ This divergence might be because 3-part proximal humeral fractures were included, and the mean age of the patients was older in our study. In addition, the mean Constant-Murley score at final follow-up in most studies usually ranged from 70 to 90 , which was identical to our results. A randomized controlled trial showed a significantly higher rate of total complications with intramedullary nails, ${ }^{15}$ but Zhu et a ${ }^{12}$ and Hardeman et $\mathrm{al}^{21}$ reported a higher complication rate when patients were treated with locking plates. In our study, the absolute number of total complications in the plate group was higher, but the total complication rates did not reach statistical difference, which were identical to those reported in a meta-analysis that concluded that total complication rates did not show statistical difference between the intramedullary nails and locking plates. ${ }^{22}$ The forward elevation and external rotation in the nail group were inferior to the plate group, but it did not reach statistical difference. The damage to the supraspinatus tendon when intramedullary nailing was done might explain the lower forward elevation and external rotation in the nail group. ${ }^{23}$

Conservative treatment was indicated in non-displaced or minimally displaced fractures with reasonable functional results and few complications. ${ }^{24}$ In the study, intramedullary nails and locking plates had comparable functional results compared to conservative treatment for 2-part proximal humeral fractures. These results are consistent with a previous work which reported that intramedullary nails and the locking plates failed to find a more beneficial clinical outcome than the conservative treatment for 2-part proximal humeral fractures. ${ }^{16}$ A multicenter randomized clinical trial on patients with displaced proximal humeral fractures involving the surgical neck concluded that surgical treatment failed 
to achieve better patient-reported clinical outcomes than nonsurgical treatment at overall or individual time points. ${ }^{25}$ In the abovementioned study, the majority of fractures were minimally displaced or 2-part fractures. Hauschild et $\mathrm{al}^{24}$ demonstrated that both conservative treatment and operative treatment (locking plates and intramedullary nails) were a safe and effective therapeutic option for 2-part proximal humeral fractures. They reported a better range of motion and pain reduction in the early postoperative course diminishes over time and became comparable at final follow-up. ${ }^{24}$ In our study, the shoulder function scores were similar among the surgical groups and the conservative groups, and the VAS scores and forward elevation were only better in the surgical groups in the management of 2-part and 3-part fractures at 6-month follow-up. However, the shoulder external rotation remained significantly lesser in the conservative group for 2-part and 3-part fractures. The pain might partially compromise the range of motion, especially the forward elevation. Moreover, the external rotation mainly depends on infraspinatus and teres minor, which are attached to the greater tuberosity of humerus. ${ }^{26,27}$ Displaced fractures were closely reduced, and the greater tuberosity was not fixed in the conservative group. Consequently, the good position of the greater tuberosity in the surgical groups might contribute to a better external rotation.

The advantages in functional outcomes favor the use of locking plates and intramedullary nails in the management of 3 -part proximal humeral fractures. Olerud et $\mathrm{al}^{28}$ carried out a randomized controlled trial on 3-part fractures in elderly patients for comparing conservative treatment with locking plates. The result indicated supportive clinical outcomes with locking plates over conservative treatment. However, another randomized controlled trial reported no differences in the functional outcome between conservative treatment and locking plate in patients $>60$ years of age with 3-part and 4-part fractures. ${ }^{29}$ However, it was difficult to interpret the comparison, because a mixed population of 3-part and 4-part fractures were analyzed together. The shoulder function scores may be influenced largely by inclusion of 4-part fractures. Initial displacement was related to progression of displacement when displaced proximal humeral fractures were treated conservatively. ${ }^{30}$ Therefore, 3 -part fractures with greater displacement preoperatively would have a potential greater progression of displacement in the conservative group than in the plate group and the nail group after surgery, and locking plates and intramedullary nails could provide more stable fixation to prevent further displacement to achieve better clinical outcomes for 3-part fractures. One clinical study showed that conservative treatment for 3-part and 4-part proximal humeral fractures in the elders $(>75$ years old) resulted in good pain relief with limited functional outcome, but the limited functional outcome did not have effect on daily life. ${ }^{31}$ The reported Constant-Murley scores were lower than those of this study $(79.07 \pm 8.39)$ for conservative treatment, which might be due to inclusion of 4-part fractures and older age of patients. Locking plates were currently used for displaced 2-, 3-, and 4-part proximal humeral fractures, but it was reported to be associated with higher complications, ranging from $16 \%$ to $64 \%{ }^{32}$ In our study, for both 2-part and 3-part fractures, although the complication rate in the plate group was obviously higher than the conservative group, no significant difference was found.

Our study had several limitations. The patients were not divided into groups randomly in this prospective study, but the basic characteristics of demographics were comparable. The surgeons and physical therapists were not blinded to the type of treatment, which might cause a bias. Besides, the short duration of follow-up might induce an underestimation of the complication rate in the long-term. Another limitation was a small sample size of our study. Therefore, larger sample prospective randomized controlled studies with long-term follow-up are warranted.

\section{Conclusion}

Similar satisfactory functional outcomes can be achieved with locking plates, intramedullary nails or conservative treatment for 2-part proximal humeral fractures in the elders. The advantages in functional outcomes favor locking plates and intramedullary nails in the management of 3-part proximal humeral fractures.

\section{Acknowledgments}

We thank Jiezhou Wu, Renlong Li and Hengda Hu (all from the Department of Orthopedics, Shanghai Tenth People's Hospital, Tongji University School of Medicine, Shanghai, China) and Xifan Li (Department of Radiology, Shanghai Tenth People's Hospital, Tongji University School of Medicine, Shanghai, China) for technical assistance and helpful discussions.

\section{Author contributions}

All authors contributed toward data analysis, drafting and critically revising the paper and agree to be accountable for all aspects of the work.

\section{Disclosure}

The authors report no conflicts of interest in this work. 


\section{References}

1. Hak DJ, Mauffrey C, Hake M, Hammerberg EM, Stahel PF. Ipsilateral femoral neck and shaft fractures: current diagnostic and treatment strategies. Orthopedics. 2015;38(4):247-251.

2. Bahrs C, Stojicevic T, Blumenstock G, et al. Trends in epidemiology and patho-anatomical pattern of proximal humeral fractures. Int Orthop. 2014;38(8):1697-1704.

3. Li Y, Zhao L, Zhu L, Li J, Chen A. Internal fixation versus nonoperative treatment for displaced 3-part or 4-part proximal humeral fractures in elderly patients: a meta-analysis of randomized controlled trials. PLoS One. 2013;8(9):e75464.

4. Maier D, Jäger M, Strohm PC, Südkamp NP. Treatment of proximal humeral fractures - a review of current concepts enlightened by basic principles. Acta Chir Orthop Traumatol Cech. 2012;79(4):307-316.

5. Hintermann B, Trouillier HH, Schafer D. Rigid internal fixation of fractures of the proximal humerus in older patients. J Bone Joint Surg Br. 2000;82(8):1107-1112.

6. Brunner F, Sommer C, Bahrs C, et al. Open reduction and internal fixation of proximal humerus fractures using a proximal humeral locked plate: a prospective multicenter analysis. J Orthop Trauma. 2009;23(3): 163-172.

7. Thanasas C, Kontakis G, Angoules A, Limb D, Giannoudis P. Treatment of proximal humerus fractures with locking plates: a systematic review. J Shoulder Elbow Surg. 2009;18(6):837-844.

8. Fialka C, Oberleitner G, Stampfl P, Brannath W, Hexel M, Vécsei V. Modification of the Constant-Murley shoulder score-introduction of the individual relative Constant score Individual shoulder assessment. Injury. 2005;36(10):1159-1165.

9. Ban I, Birkelund L, Palm H, Brix M, Troelsen A. Circumferential wires as a supplement to intramedullary nailing in unstable trochanteric hip fractures: 4 reoperations in 60 patients followed for 1 year. Acta Orthop. 2012;83(3):240-243.

10. Füchtmeier B, May R, Hente R, et al. Proximal humerus fractures: a comparative biomechanical analysis of intra and extramedullary implants. Arch Orthop Trauma Surg. 2007;127(6):441-447.

11. Gradl G, Dietze A, Kääb M, Hopfenmüller W, Mittlmeier T. Is locking nailing of humeral head fractures superior to locking plate fixation? Clin Orthop Relat Res. 2009;467(11):2986-2993.

12. Zhu Y, Lu Y, Shen J, Zhang J, Jiang C. Locking intramedullary nails and locking plates in the treatment of two-part proximal humeral surgical neck fractures: a prospective randomized trial with a minimum of three years of follow-up. J Bone Joint Surg Am. 2011;93:159-168.

13. Egol KA, Ong CC, Walsh M, Jazrawi LM, Tejwani NC, Zuckerman JD. Early complications in proximal humerus fractures (OTA Types 11) treated with locked plates. J Orthop Trauma. 2008;22(3):159-164.

14. de Morton NA. The PEDro scale is a valid measure of the methodological quality of clinical trials: a demographic study. Aust J Physiother. 2009;55(2):129-133.

15. Gracitelli ME, Malavolta EA, Assunção JH, et al. Locking intramedullary nails compared with locking plates for two- and three-part proximal humeral surgical neck fractures: a randomized controlled trial. J Shoulder Elbow Surg. 2016;25(5):695-703.
16. Tamimi I, Montesa G, Collado F, et al. Displaced proximal humeral fractures: when is surgery necessary? Injury. 2015;46(10):1921-1929.

17. Court-Brown CM, Garg A, McQueen MM. The epidemiology of proximal humeral fractures. Acta Orthop Scand. 2001;72(4):365-371.

18. Barlow JD, Sanchez-Sotelo J, Torchia M. Proximal humerus fractures in the elderly can be reliably fixed with a "hybrid" locked-plating technique. Clin Orthop Relat Res. 2011;469(12):3281-3291.

19. Liu QH, Sun W, Zhou JL, et al. A new approach for the treatment of proximal humeral fractures using the TRIGEN proximal humeral nail. Eur J Orthop Surg Traumatol. 2014;24(4):467-474.

20. Mao F, Zhang DH, Peng XC, Liao Y. Comparison of surgical versus non-surgical treatment of displaced 3- and 4-part fractures of the proximal humerus: a meta-analysis. J Invest Surg. 2015;28(4):215-224.

21. Hardeman F, Bollars P, Donnelly M, Bellemans J, Nijs S. Predictive factors for functional outcome and failure in angular stable osteosynthesis of the proximal humerus. Injury. 2012;43(2):153-158.

22. Wang G, Mao Z, Zhang L, et al. Meta-analysis of locking plate versus intramedullary nail for treatment of proximal humeral fractures. J Orthop Surg Res. 2015;10:122.

23. Chapman JR, Henley MB, Agel J, Benca PJ. Randomized prospective study of humeral shaft fracture fixation: intramedullary nails versus plates. J Orthop Trauma. 2000;14(3):162-166.

24. Hauschild O, Konrad G, Audige L, et al. Operative versus non-operative treatment for two-part surgical neck fractures of the proximal humerus. Arch Orthop Trauma Surg. 2013;133(10):1385-1393.

25. Rangan A, Handoll H, Brealey S, et al; PROFHER Trial Collaborators. Surgical vs nonsurgical treatment of adults with displaced fractures of the proximal humerus: the PROFHER randomized clinical trial. JAMA. 2015;313(10):1037-1047.

26. Burkhart KJ, Dietz SO, Bastian L, Thelen U, Hoffmann R, Müller LP. The treatment of proximal humeral fracture in adults. Dtsch Arztebl Int. 2013;110(35-36):591-597.

27. Maier D, Jaeger M, Izadpanah K, Strohm PC, Suedkamp NP. Proximal humeral fracture treatment in adults. J Bone Joint Surg Am. 2014;96(3):251-261.

28. Olerud P, Ahrengart L, Ponzer S, Saving J, Tidermark J. Internal fixation versus nonoperative treatment of displaced 3-part proximal humeral fractures in elderly patients: a randomized controlled trial. J Shoulder Elbow Surg. 2011;20(5):747-755.

29. Fjalestad T, Hole MØ, Hovden IA, Blücher J, Strømsøe K. Surgical treatment with an angular stable plate for complex displaced proximal humeral fractures in elderly patients: a randomized controlled trial. J Orthop Trauma. 2012;26(2):98-106.

30. Foruria AM, Marti M, Sanchez-Sotelo J. Proximal humeral fractures treated conservatively settle during fracture healing. J Orthop Trauma. 2015;29(2):e24-e30.

31. Torrens C, Corrales M, Vilà G, Santana F, Cáceres E. Functional and quality-of-life results of displaced and nondisplaced proximal humeral fractures treated conservatively. J Orthop Trauma. 2011;25(10): 581-587.

32. Bali K, Krishnan V, Aggarwal S. A prospective clinical study of proximal humerus fractures treated with a locking proximal humerus plate. J Orthop Trauma. 2011;25(4):e42.
Clinical Interventions in Aging

\section{Publish your work in this journal}

Clinical Interventions in Aging is an international, peer-reviewed journal focusing on evidence-based reports on the value or lack thereof of treatments intended to prevent or delay the onset of maladaptive correlates of aging in human beings. This journal is indexed on PubMed Central, MedLine,

\section{Dovepress}

CAS, Scopus and the Elsevier Bibliographic databases. The manuscript management system is completely online and includes a very quick and fair peer-review system, which is all easy to use. Visit http://www.dovepress. com/testimonials.php to read real quotes from published authors. 